\title{
Cryptococcal meningitis epidemiology: 17 years of experience in a State of the Brazilian Pantanal
}

\author{
Joslaine de Oliveira Nunes ${ }^{[1]}$, Rosianne Assis de Sousa Tsujisaki ${ }^{[2]}$, \\ Maína de Oliveira Nunes ${ }^{[3]}$, Gláucia Moreira Espíndola Lima ${ }^{[3]}$, Anamaria Mello Miranda \\ Paniago ${ }^{[2]}$, Elenir Rose Jardim Cury Pontes ${ }^{[2]}$ and Marilene Rodrigues Chang ${ }^{[1],[4]}$
}

\author{
[1]. Programa de Pós-Graduação Stricto Senso em Saúde e Desenvolvimento na Região Centro-Oeste, Faculdade de Medicina, \\ Universidade Federal de Mato Grosso do Sul, Campo Grande, MS, Brasil. \\ [2]. Programa de Pós-Graduação Stricto Senso em Doenças Infecciosas e Parasitárias, Faculdade de Medicina, \\ Universidade Federal de Mato Grosso do Sul, Campo Grande, MS, Brasil. \\ [3]. Laboratório de Micologia, Hospital Universitário Maria Aparecida Pedrossian, \\ Universidade Federal de Mato Grosso do Sul, Campo Grande, MS, Brasil. \\ [4]. Laboratório de Pesquisa Microbiológica, \\ Universidade Federal de Mato Grosso do Sul, Campo Grande, MS, Brasil.
}

\begin{abstract}
Introduction: This study aimed to describe cryptococcal meningitis (CM) cases and the associated demographic, clinical, and microbiological data obtained from cities in the State of Mato Grosso do Sul in the Midwestern region of Brazil. Methods: The data from 129 patients with laboratory-confirmed CM admitted from 1997 to 2014 were retrospectively reviewed. The molecular types of Cryptococcus neoformans and Cryptococcus gattii isolated from cerebrospinal fluid were analyzed to determine their geographic distribution. Results: The patients had a mean age of 37 years and consisted mostly of men (76.7\%). Most of the Cryptococcus isolates were obtained from patients infected with human immunodeficiency virus (HIV) and included 105 (87.5\%) and $5(55.6 \%)$ isolates of $C$. neoformans and C. gattii complexes, respectively. A restriction fragment length polymorphism (RFLP) analysis of URA5 revealed that most of the isolates were C. neoformans molecular type VNI (89.1\%), whereas the molecular types VGII (7\%) and VNII (3.9\%) were observed less frequently. Notably, $65 \%$ of the cases with a time from symptom onset to laboratory diagnosis of more than 60 days resulted in fatalities, and sequelae were observed among the patients who survived. Conclusions: The present study documents the occurrence of neurocryptococcosis, which is mainly caused by $C$. neoformans VNI, in Mato Grosso do Sul, Brazil, with probable autochthonous cases in the Brazilian Pantanal, the world's largest tropical wetland, and a biome where cryptococcosis has not yet been explored.
\end{abstract}

Keywords: Cryptococcosis. Aids. Cryptococcus. Molecular typing. Cryptococcus neoformans. Cryptococcus gattii.

\section{INTRODUCTION}

Cryptococcosis is a systemic mycosis caused primarily by Cryptococcus neoformans species complex, which includes the molecular types VNI, VNII, VNB, VNIII, and VNIV, and the Cryptococcus gattii species complex, which includes the molecular types VGI, VGII, VGIII, and VGIV ${ }^{1-3}$. Differences in geographical distribution, ecological niches, epidemiology, clinical presentation, and molecular characteristics have been observed among various Cryptococcus spp ${ }^{4}$.

The Pantanal is the world's largest tropical wetland area and home to approximately 3,500 plants species and more than 730 species of birds, many of which undergo intercontinental

Corresponding author: Ms. Joslaine de Oliveira Nunes.

e-mail: joslaine.nunes@bol.com.br

Received 26 February 2018

Accepted 21 June 2018 and intracontinental migration ${ }^{5,6}$, which may influence the geographic distribution of Cryptococcus spp.

Yeasts are distributed in the environment and can infect the human body primarily through the respiratory tract, causing lung disease in some cases. Cryptococcal meningitis is the most common clinical manifestation due to the remarkable tropism of Cryptococcus spp. toward the central nervous system ${ }^{7,8}$.

Worldwide, the epidemiology of cryptococcosis has been influenced by acquired immunodeficiency syndrome (AIDS) $)^{8,9}$. In Latin American countries, 54.4 cases of cryptococcal meningitis are estimated to occur annually in every set of 1,000 cases of AIDS ${ }^{10}$. In Brazil, the disease has been identified as one of the most life-threatening fungal infections in this group of patients ${ }^{11}$. The mortality rates associated with cryptococcal meningitis vary regionally. Despite improvements in medical care and antifungal treatment, a significant decrease in mortality, which is estimated to be greater than $50 \%$ in less developed countries, has not been observed to date ${ }^{10,12,13}$. 
Currently, there are limited data on the molecular epidemiology of cryptococcal meningitis in the Midwestern region of Brazil, and this study aimed to provide new information to the scientific community.

\section{METHODS}

We retrospectively analyzed 129 cases of cryptococcal meningitis diagnosed at the University Hospital, Federal University of Mato Grosso do Sul, Campo Grande, the capital of Mato Grosso do Sul, from May 1997 to May 2014.

The University Hospital is a 255-bed university teaching reference center for the diagnosis and treatment of infectious diseases in the entire State of Mato Grosso do Sul. This state ranked sixth in terms of tertiary extension, with an area of $357,145,534 \mathrm{~km}^{2}$, which corresponds to $4.19 \%$ of the total area of Brazil $\left(8,5515,767,049 \mathrm{~km}^{2}\right)$ and $22.2 \%$ of the area of the Midwest region. This state was estimated to have 2,651,235 inhabitants in 2015, giving the state a ranking of 21 in terms of population in Brazil ${ }^{14,15}$.

The cases were selected from a database and included 72 cases diagnosed between 1997 and 2005 (participants of the study conducted by Lindemberg et al.) and 57 cases diagnosed from 2006 to $2014^{16}$.

Cryptococcal meningitis is identified based on the clinical features of meningeal infection and the isolation of Cryptococcus spp. from cerebrospinal fluid (CSF) culture.

Patient characteristics were obtained from medical records and the Microbiological Research Laboratory database. Demographic (gender, age, occupation, and area of residence) and clinical characteristics [human immunodeficiency virus (HIV) coinfection, previous use of antiretroviral therapy, time elapsed between symptom onset of cryptococcosis to diagnosis, length of hospital stay, and clinical outcomes during the hospitalization period], and the species and molecular type of Cryptococcus spp. were investigated.

\section{Ethical considerations}

The study was approved by the institutional ethics committee.

In this study, polymerase chain reaction (PCR)restriction fragment length polymorphism (RFLP) was used to distinguish $C$. neoformans and C. gattii species. The URA5 gene was amplified by PCR using the primers URA5 (5' ATGTCCTCCCAAGCCCTCGACTCCG 3') and SJ01 (5' TTAAGACCTCTGAACACCGTACTC 3'). The amplified PCR product was double digested using the HhaI and Sau96I enzymes, as previously described ${ }^{3}$. The RFLP profiles were visually analyzed by comparison with reference strains.

The data were analyzed using the Statistical Package for the Social Sciences (SPSS) software version 23.0 (IBM Corporation, Armonk, NY, USA). Normality was assessed using the Shapiro-Wilk test. The groups were compared using Student's $t$-test or the Mann-Whitney $\mathrm{U}$ test for continuous variables and Pearson's chi-square test or Fisher's exact test for categorical variables. A significance level of 0.05 was adopted.

\section{RESULTS}

A total of 129 CSF isolates were recovered during the 17year study period. One hundred eleven $(86 \%)$ of the samples were obtained from AIDS patients, and $63(56.8 \%)$ of these had cluster of differentiation 4 (CD4) counts less than 200 cells $/ \mathrm{mm}^{3}$.

Ninety-nine $(76.7 \%)$ patients were men, and the mean [standard deviation] age of the patients was 37 [11] years (range: $10-74$ years). With regard to occupation, $15.5 \%(20 / 129)$ of the patients were general service providers, $13.2 \%$ (17/129) were construction workers, $10.8 \%(14 / 129)$ were household workers, $7.8 \%(10 / 129)$ were rural workers, and $16.3 \%(21 / 129)$ had other occupations; however, the profession of 36.4\% (47/129) of the cases was not recorded. Other patient characteristics are summarized in Table 1.

No significant differences were observed in the sex ratio, time from symptom onset to diagnosis, and patient outcomes between patients with HIV infection and those without HIV infection. However, patient age, area of residence, and cryptococcal species responsible for causing the infection showed significant differences between patients with AIDS and HIV-negative patients ( $P$-value $<0.05)$.

The mean age of the AIDS patients was 35.7 [9.5] years, which is lower than the mean age of the HIV-negative patients, which was 44.6 [14.9] years (Student's $t$-test; $P$-value $<0.01$ ).

Thirty-five (41.6\%) patients with a previous diagnosis of AIDS reported the use of highly active antiretroviral therapy (HAART) (Figure 1), but only 20.2\% (17/84) regularly received this therapy.

The average time from symptom onset to the diagnosis of cryptococcal meningitis was 41 [60.9] days (range: 1-297 days). A total of $69(53.5 \%)$ patients survived, and $60(46.5 \%)$ died. Although not statistically significant, $65 \%(13 / 20)$ of the patients with a time from symptom onset to the laboratory diagnosis of cryptococcosis of more than 60 days died, and $42.8 \%$ (39/91) of the patients who received a laboratory diagnosis less than 60 days after the onset of disease symptoms died. The period from the onset of disease symptoms to laboratory diagnosis could not be identified in 18 cases. Patients who were discharged from the hospital $(\mathrm{n}=70)$ developed various complications, including visual sequelae $(\mathrm{n}=5 ; 7.1 \%)$, cognitive impairment $(\mathrm{n}=4 ; 5.7 \%)$, and hearing loss $(\mathrm{n}=1 ; 1.4 \%)$.

Molecular typing showed that most of the isolates obtained from the studied region belonged to $C$. neoformans molecular type VNI $(\mathrm{n}=115 ; 89.1 \%)$; however, VNII $(\mathrm{n}=5 ; 3.9 \%)$ and C. gattii VGII ( $\mathrm{n}=9 ; 7 \%)$ types were also found (Figure 2).

Three out of five $C$. neoformans VNII strains were isolated from patients originating from two other states: São Paulo $(\mathrm{n}=1)$ and Paraná $(\mathrm{n}=2)$. The molecular types of Cryptococcus spp. according to HIV infection status and clinical outcomes are described in Table 2.

\section{DISCUSSION}

This study is relevant because it describes the epidemiological aspects of cryptococcal meningitis cases during a period of almost two decades from cities of Mato Grosso do Sul state. 
TABLE 1: Demographic and clinical characteristics of patients with cryptococcal meningitis who either had AIDS or were HIV negative.

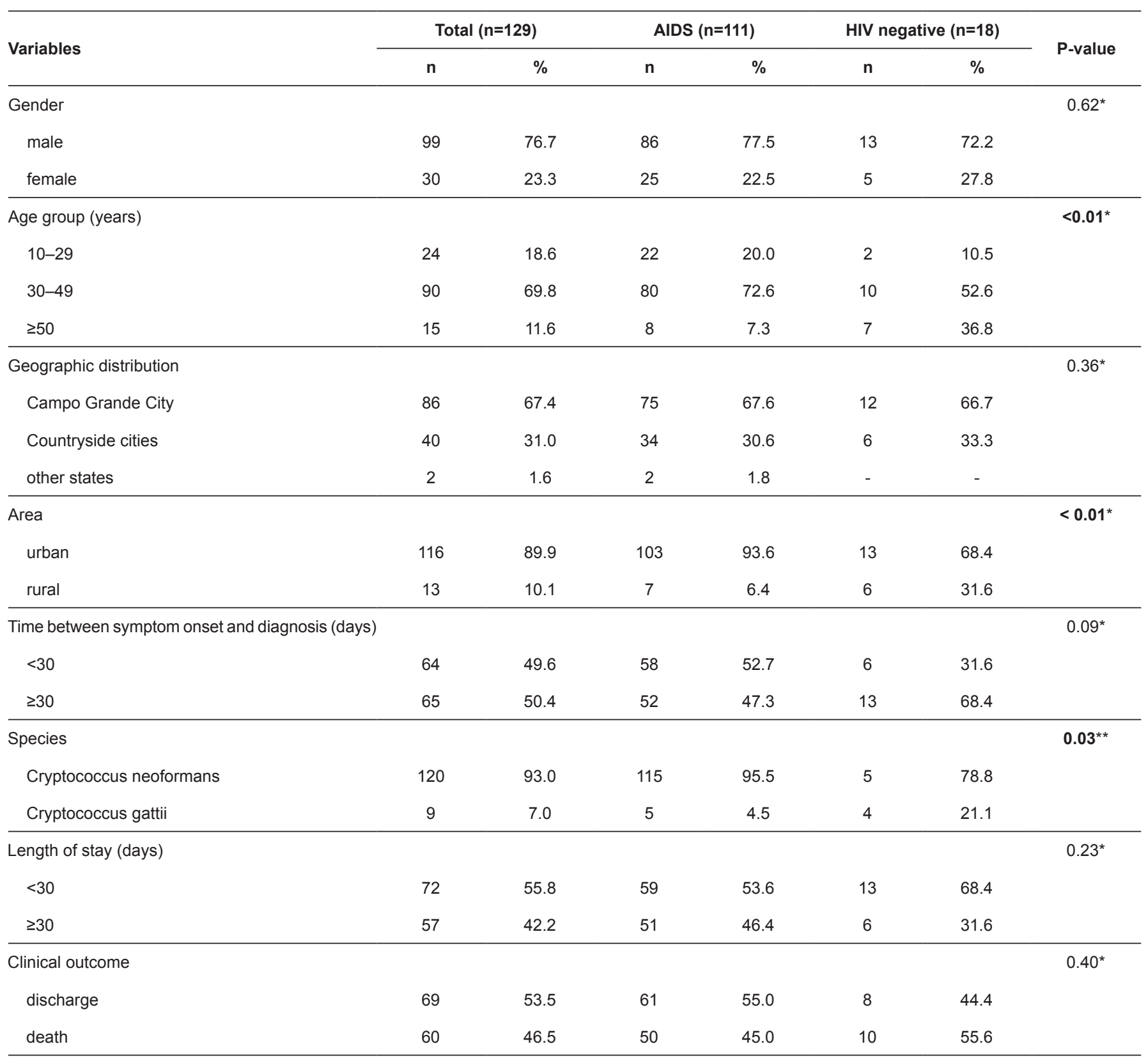

AIDS: acquired immunodeficiency syndrome; HIV: human immunodeficiency virus. ${ }^{*}$ Fisher's exact test. ${ }^{* *}$ Chi-squared test.

Although numerous studies have investigated cryptococcal meningitis throughout the world, few studies have been conducted in this large Brazilian territory.

The results of this study showed that approximately 7.6 cases of cryptococcal meningitis were diagnosed annually at the MAPUH, and the diagnosis rate was six-fold higher in AIDS patients than in HIV-negative patients. In Goiás, another state of the Brazilian Midwest, Souza et al. ${ }^{17}$ described a similar annual incidence rate (5.9) of cryptococcal meningitis.

Corroborating the findings of previous studies, a greater involvement of men $(76.7 \%)$ than women was observed in this study. Approximately $61 \%-82 \%$ of the population has been found to be affected with cryptococcal meningitis, as reported in several studies, indicating that men might be more susceptible to infection by Cryptococcus $\operatorname{spp}^{17-19}$. The underlying causes for this increased susceptibility may be related to the following factors: occupational exposure; behavioral aspects, including alcoholism and smoking; and HIV infection ${ }^{12,20}$. Hormonal and immunological factors that predispose men to infection by Cryptococcus spp have also been investigated, and testosterone seems to induce greater capsule production and lower macrophage efficiency ${ }^{21}$. 


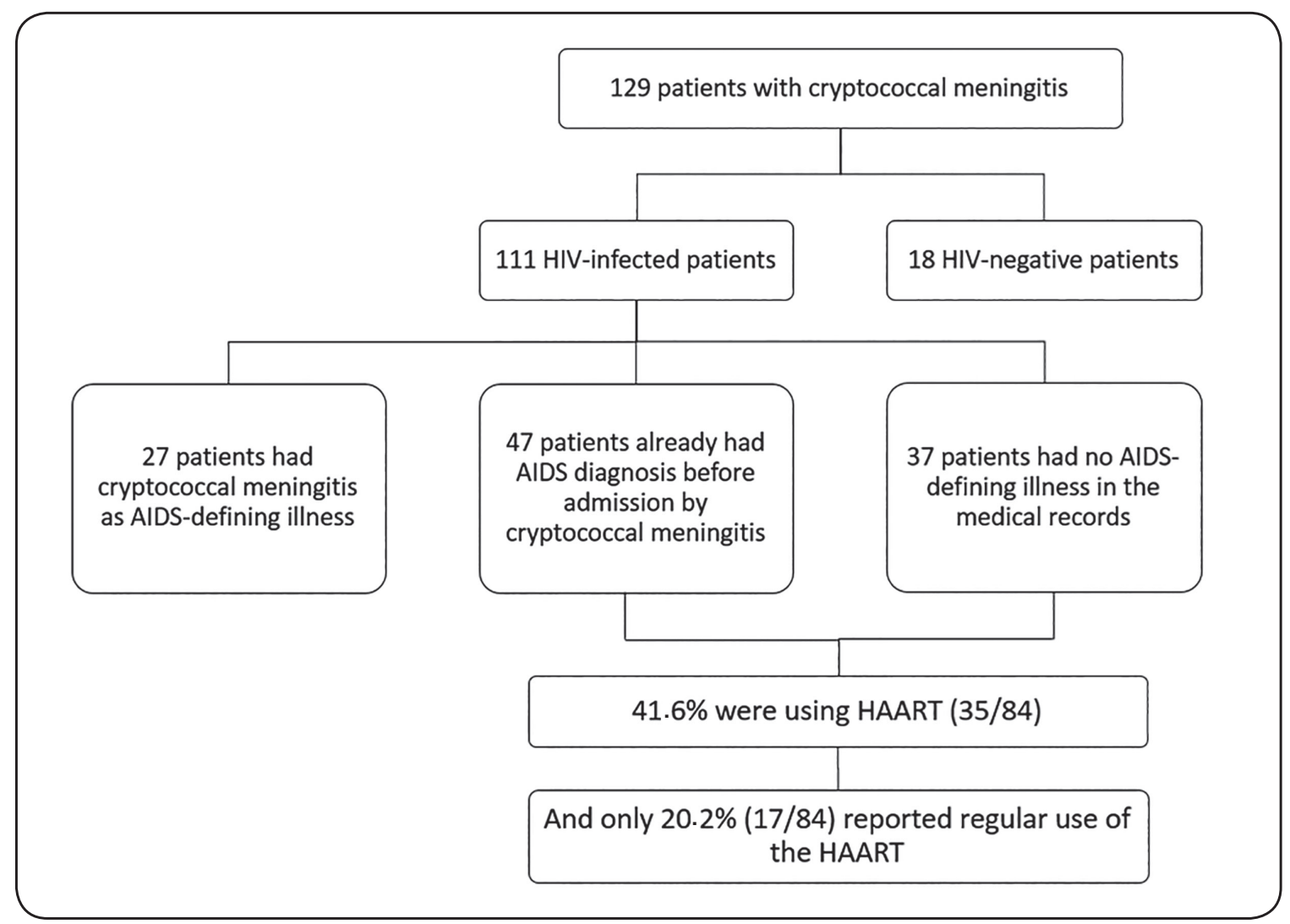

FIGURE 1: Distribution of patients with cryptococcal meningitis according to HIV infection status and antiretroviral therapy use. HIV: human immunodeficiency virus; AIDS: acquired immunodeficiency syndrome; HAART: highly active antiretroviral therapy.

TABLE 2: Patients with cryptococcal meningitis according molecular type, HIV infection status, and clinical outcomes.

\begin{tabular}{|c|c|c|c|c|c|}
\hline \multirow{2}{*}{ Variables } & \multicolumn{2}{|c|}{ Cryptococcus neoformans } & \multicolumn{2}{|c|}{ Cryptococcus gattii } & \multirow{2}{*}{$P$-value } \\
\hline & $\mathbf{n}$ & $\%$ & $\mathbf{n}$ & $\%$ & \\
\hline AIDS & & & & & 0.03 \\
\hline yes & 105 & 87.5 & 5 & 55.6 & \\
\hline Clinical outcomes & & & & & 0.04 \\
\hline discharged & 62 & 51.7 & 8 & 88.9 & \\
\hline death & 58 & 48.3 & 1 & 11.1 & \\
\hline
\end{tabular}

HIV: human immunodeficiency virus; AIDS: acquired immunodeficiency syndrome. *Fisher's exact test. 


\section{State of Mato Grosso do Sul: municipalities}

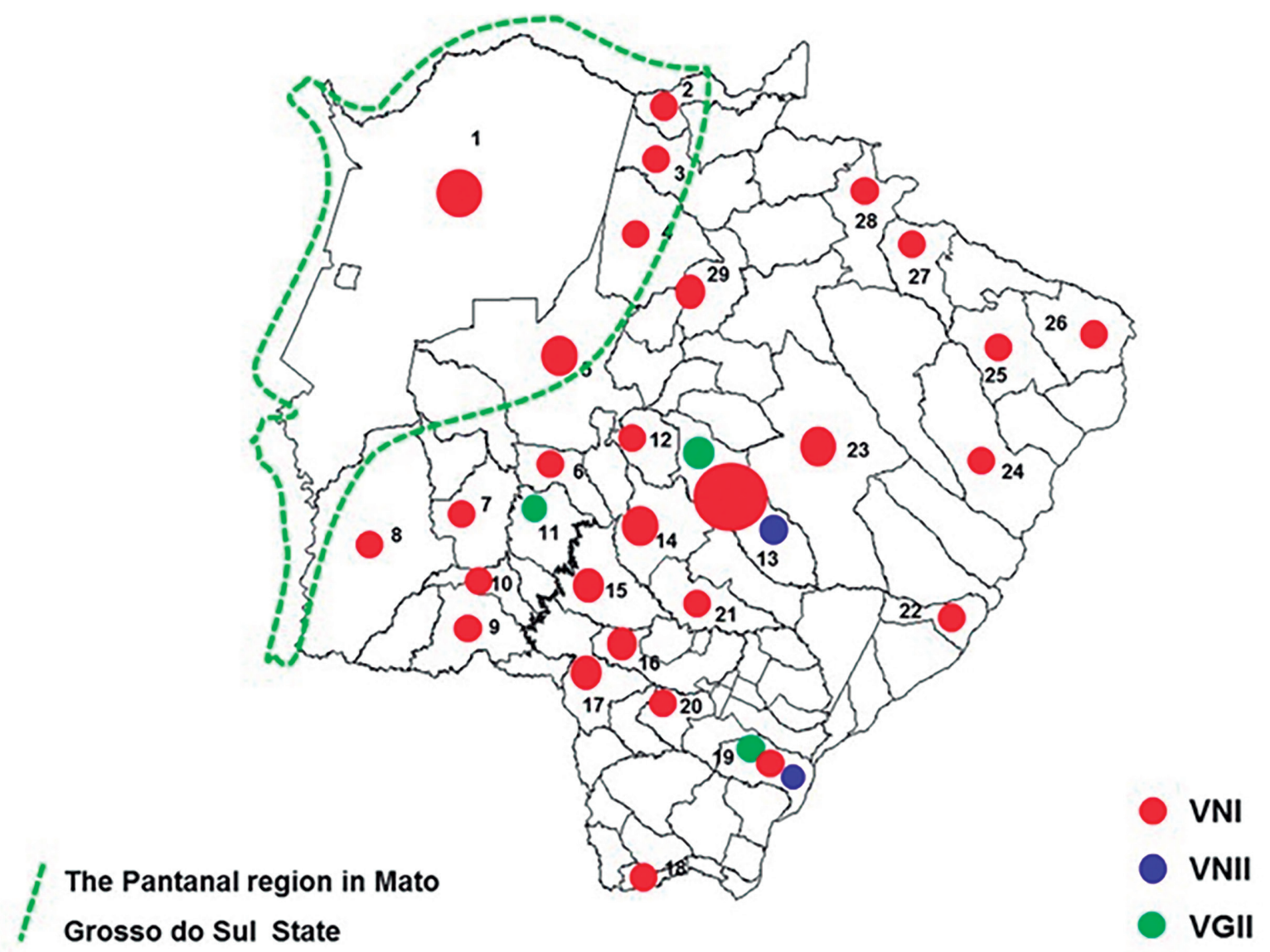

\section{Legend}

1: Corumbá (VNI); $n=3$

2: Sonora (VNI); $n=1$

3: $\operatorname{Coxim}(V N I) ; n=1$

4: Rio Verde de Mato Grosso(VNI); $n=1$

5: Aquidauana (VNI); $n=2$

6: Anastácio (VNI); $n=1$

7: Bonito (VNI); $n=1$

8: Porto Murtinho (VNI); $n=1$

9: Bela Vista (VNI); $n=1$

10: $\operatorname{Jardim}(V N I) ; n=1$

11: Nioaque (VGII); $n=1$

12: Terenos (VNI); $n=1$

13: Campo Grande (VNI, VNII, VGII); $n=75,4,6$

14: Sidrolândia (VNI); $n=2$
15: Maracaju(VNI); $n=2$

16: Dourados (VNI); $n=2$

17: Ponta Porã (VNI); $n=2$

18: Sete Quedas (VNI); $n=1$

19: Naviraí (VNI, VNII, VGII); $n=1,1,1$

20: Caarapó(VNI); $n=1$

21: Rio Brilhante (VNI); $n=1$

22: Bataguassu (VNI); $n=1$

23: Ribas do Rio Pardo (VNI); $n=2$

24:Três Lagoas (VNI); $n=1$

25: Inocência (VNI); $n=2$

26: Paranaíba (VNI); $n=1$

27: Chapadão do Sul (VNI); $n=1$

28: Costa Rica (VNI); $n=1$

29: São Gabriel do Oeste (VNI); $n=2$

FIGURE 2: Distribution of Cryptococcus neoformans and Cryptococcus gattii molecular types in the cities of Mato Grosso do Sul according to the place of residence of the patients with cryptococcal meningitis. 
Previous studies have shown that cryptococcosis often affects adults, especially those with altered cellular immunity ${ }^{17,18,21}$. Worldwide, men aged 30-45 years are at greater risk of developing cryptococcal meningitis ${ }^{12,22,23}$. In accordance with the global trends, cryptococcal meningitis in the Mato Grosso do Sul State is closely related to HIV infection ${ }^{16,24}$.

The number of patients aged older than 50 years was proportionally higher in the HIV-negative group. Aging increases an individual's susceptibility to infectious diseases, even those without HIV, due to the comorbidities associated with anatomical and physiological changes and poor immune responses ${ }^{25}$.

Only three $(2.3 \%)$ cases of cryptococcal meningitis in children were recorded during the 17-year study period. A similar prevalence was found in the Rio Grande do Sul and Rio de Janeiro states ${ }^{22,26}$.

The reason why children are less affected by cryptococcosis remains unknown ${ }^{27}$. In the Northern and Northeastern regions of Brazil, primarily the States of Bahia (32\%), Pará (24\%), and Piauí (9.5\%), a high prevalence of cryptococcosis in children was reported, and a majority of these cases are children living in rural areas ${ }^{18,28,29}$.

This study showed an association between living in a rural area and an HIV-negative status. Cryptococcosis should be investigated in patients living in endemic areas who have these characteristics.

Confirming the cosmopolitan nature of this disease, most patients lived in urban areas, primarily Campo Grande City. This finding may have been obtained because the urban population in Mato Grosso do Sul is almost six-fold higher than the rural population according to the census conducted in 2010 by the Brazilian Institute of Geography and Statistics ${ }^{14,15}$.

Another reason for this finding is that urban centers are often important ecological niches of domestic pigeons (Columba livia), which are natural reservoirs of Cryptococcus sp. In fact, this yeast was observed in the excreta of captive birds and in public areas that are commonly used by humans $\mathrm{s}^{30-32}$.

Vidal et al. ${ }^{11}$ stated that in Latin American countries, those who live in poverty and are affected by opportunistic diseases have limited access to medical care. Although the present study did not aim to study the socioeconomic status of patients, in Brazil, the average amount of time from symptom onset to the diagnosis of cryptococcosis ranges from several days to several months, as observed in the studied population ${ }^{18,28}$. Delays in diagnosis may reflect the difficulties that patients face accessing health services as well as the limited diagnostic resources (serological tests, microscopic findings, and culture) available in Mato Grosso do Sul cities. From this perspective, the number of cryptococcal meningitis cases in the South Pantanal region may be underestimated. Focused efforts to improve the current diagnostic capacity and identify the agents of cryptococcal disease are urgently warranted.

Notably, in the present study, $65 \%$ of the cases involving patients who received their laboratory diagnosis more than 60 days after symptom onset resulted in fatalities, and sequelae were observed among those who survived. Because the disease has a high mortality rate if not diagnosed and treated appropriately, we reaffirm the importance of early diagnosis for survival and better prognosis.

In the United States, the mortality associated with cryptococcosis seems to be decreasing ${ }^{27}$. However, in less developed countries, the estimated mortality rate is $55 \%$, and this rate is even higher in Sub-Saharan Africa (70\%), where the occurrence of AIDS is high ${ }^{10}$.

Overall, approximately 957,900 cases (range: 371,700 $1,544,000$ ) of cryptococcal meningitis occur every year, and 624,700 deaths (range: 125,000-1,124,900) occur within 3 months after the onset of infection. In Latin America, studies have investigated the factors responsible for the high mortality of AIDS-related cryptococcal meningitis ${ }^{11}$. In Brazil, the mortality rate ranged from $32 \%$ to $60 \%{ }^{18,33,34}$; however, there was limited information on the fatality rate of HIV-infected patients with cryptococcal meningitis in the Midwestern region of Brazil ${ }^{16,23}$.

The World Health Organization recommended the early diagnosis and treatment of HIV (HAART) as one of the most important and cost-effective preventive strategies for reducing the incidence and mortality associated with cryptococcal meningitis ${ }^{11}$. When available, screening tests, including investigations of the presence of cryptococcal capsular antigen in asymptomatic and symptomatic patients, also contribute to the optimization of the diagnosis and treatment of cryptococcosis ${ }^{35}$.

Various studies have shown that the incidence of cryptococcal meningitis can be minimized by the regular use of HAART ${ }^{8,11}$. Late and incomplete access to antiretroviral therapy may have resulted in the high rate of cryptococcal infection observed in our study.

Previous studies have shown that the VNI molecular pattern is the most common pattern worldwide, whereas VNII was observed in $1 \%-16 \%$ of cases reported in southern continents, such as South America, Africa, and Oceania ${ }^{2,3}$. C. gattii VGII was also observed in South America, North America ${ }^{3,27,36}$, and Oceania $^{2}$. Interestingly, in Brazil, several regions exhibited a high prevalence of the VNI molecular type and sporadic cases of the VNII and VGII molecular types s $^{3,16,29,37,38}$. The results obtained in this study add new information to the sparsely available data on the molecular epidemiology of cryptococcal meningitis in the Midwestern region of Brazil. The predominance of the VNI molecular type and the identification of the VGII molecular type have been described in the States of Goiás and Mato Grosso as well as other Brazilian states ${ }^{16,37}$ where VGII is endemic ${ }^{38}$, except for the states in the North and Northeast region.

This is the first report to describe the molecular types of Cryptococcus causing cryptococcal meningitis in Campo Grande, Mato Grosso do Sul. Similar to the findings of a previous study ${ }^{24}$, VNI was observed throughout the state. We highlight the isolation of VNII in patients from Campo Grande and Naviraí, cities in close proximity to São Paulo State, where this molecular type was previously described ${ }^{38-40}$.

In addition to Campo Grande and Nioaque City, the VGII molecular type was also found in Naviraí, which borders 
Paraná State, where VGII was previously reported ${ }^{38}$. Naviraí and Campo Grande are the only cities where three molecular types (VNI, VNII, and VGII) were detected. Further studies should be conducted to investigate this relation.

One of the primary limitations of our study is that it employed a cross-sectional design, and this type of design precludes the analysis of causal relations and only suggests associations between various variables. Another primary limitation is that a convenient sample was used, which makes it difficult to extrapolate the results to a larger population.

In conclusion, the present study documents the occurrence of neurocryptococcosis, which is mainly caused by $C$. neoformans VNI, in Mato Grosso do Sul, Brazil, with probable autochthonous cases in the Pantanal, a biome where cryptococcosis has not yet been explored. The time from symptom onset to clinical diagnosis is crucial for patient recovery but is largely dependent on the patient's access to healthcare and on the available diagnostic resources available.

\section{Acknowledgments}

The authors thank the Mycology Laboratory team of the University Hospital, Federal University of Mato Grosso do Sul.

\section{Conflict of interest}

The authors declare that there is no conflict of interest.

\section{Financial support}

Financial support was provided by the Fundação de Apoio ao Desenvolvimento do Ensino, Ciência e Tecnologia do Estado de Mato Grosso do Sul.

\section{REFERENCES}

1. Kwon-Chung KJ, Bennett JE, Wickes BL, Meyer W, Cuomo CA, Wollenburg KR, et al. The case for adopting the "species complex" nomenclature for the etiologic agents of cryptococcosis. mSphere. 2017;2(1):pii:e00357-16.

2. Cogliati M. Global molecular epidemiology of Cryptococcus neoformans and Cryptococcus gattii: an atlas of the molecular types. Scientifica. 2013;2013:1-23.

3. Meyer W, Castañeda A, Jackson S, Huynh M, Castañeda E, IberoAmerican Cryptococcal Study Group. Molecular typing of IberoAmerican Cryptococcus neoformans isolates. Emerg Infect Dis. 2003;9(2):189-95.

4. Kwon-Chung KJ, Varma A. Do major species concepts support one, two or more species within Cryptococcus neoformans? FEMS Yeast Res. 2006;6 (4):574-87.

5. Pott A, Pott VJ. Plants of Pantanal. Brasília: EMBRAPA-SPI; 1997. $320 \mathrm{p}$.

6. Nunes AP, Tomas WM. Aves migratórias e nômades ocorrentes no Pantanal. $1^{\text {a }}$ edition. Corumbá: EMBRAPA Pantanal; 2008. 124p.

7. Jackson A, Powderly WG. Cryptococcal infection. Handb Clin Neurol. 2007;85:159-67.

8. Sloan DJ, Parris V. Cryptococcal meningitis: epidemiology and therapeutic options. Clin Epidemiol. 2014;6:169-82.
9. Rajasingham R, Smith RM, Park BJ, Jarvis JN, Govender NP, Chiller TM, et al. Global burden of disease of HIV-associated cryptococcal meningitis: an updated analysis. The Lancet infectious diseases. 2017;17(8):873-81.

10. Park BJ, Wannemuehler KA, Marston BJ, Govender N, Pappas PG, Chiller TM. Estimation of the current global burden of cryptococcal meningitis among persons living with HIV/AIDS. Aids. 2009;23(4):525-30.

11. Vidal JE, Oliveira ACP, Dauar RF, Boulware DR. Strategies to reduce mortality and morbidity due to AIDS-related cryptococcal meningitis in Latin America. Braz J Infect Dis. 2013;17(3):353-62.

12. Chan M, Lye D, Win MK, Chow A, Barkham T. Clinical and microbiological characteristics of cryptococcosis in Singapore: predominance of Cryptococcus neoformans compared with Cryptococcus gattii. Int J Infect Dis. 2014;26:110-15.

13. Jarvis JN, Bicanic T, Loyse A, Namarika D, Jackson A, Nussbaum JC, et al. Determinants of mortality in a combined cohort of 501 patients with HIV-associated cryptococcal meningitis: implications for improving outcomes. Clin Infect Dis. 2014;58 (5):736-45.

14. Secretaria de Estado de Meio Ambiente e Desenvolvimento Econômico (SEMADE). Mato Grosso do Sul. Perfil Estatístico de Mato Grosso do Sul, 2015. $1^{\text {st }}$ edition. Campo Grande: SEMADE; 2015. 111p.

15. Instituto Brasileiro de Geografia e Estatística (IBGE). Censo 2010. Brasília: IBGE; 2010; Atualizado em: 15 de junho de 2016; citado em: 15 de Junho de 2018. Disponível em: https://censo2010.ibge.gov. $\mathrm{br} /$ sinopse/index.php?dados $=8$

16. Lindenberg ASC, Chang MR, Paniago AMM, Lazéra MS, Moncada PMF, Bonfim GF, et al. Clinical and epidemiological features of cryptococcosis in Mato Grosso do Sul, Brazil. Rev Inst Med Trop Sao Paulo. 2008;50(2):75-8.

17. Souza LKH, Costa CR, Lisboa OFF, Abrão FY, Silva TC, Tremea $\mathrm{CM}$, et al. Clinical and microbiological features of cryptococcal meningitis. Rev Soc Bras Med Trop. 2013;46(3):343-7.

18. Barragan NC, Sorvillo F, Kuo T. Cryptococcosis $\square$ related deaths and associated medical conditions in the United States. 2000-2010. Mycoses. 2014;57(12):741-6.

19. Darzé C, Lucena R, Gomes I, Melo A. Características clínicas e laboratoriais de 104 casos de meningoencefalite criptocócica. Rev Soc Bras Med Trop. 2000;33(1):21-6.

20. Sipsas NV, Kontoyiannis DP. Occupation, lifestyle, diet, and invasive fungal infections. Infection. 2008;36(6):515-25

21. Mcclelland EE, Hobbs LM, Rivera J, Casadevall A, Potts WK, Smith JM, et al. The role of host gender in the pathogenesis of Cryptococcus neoformans infections. PLoS One. 2013;8(5):e63632.

22. Kaocharoen S, Ngamskulrungroj P, Firacative C, Trilles L, Piyabongkarn D, Banlunara W, et al. Molecular epidemiology reveals genetic diversity amongst isolates of Cryptococcus neoformans/C. gattii species complex in Thailand. PLoS Negl Trop Dis. 2013;7(7):e22973.

23. Leal AL, Faganello J, Fuentefria AM, Boldo JT, Bassanesi MC, Vainstein MH. Epidemiological profile of cryptococcal meningitis patients in Rio Grande do Sul, Brazil. Mycopathologia. 2008;166(2):71-5.

24. Tsujisaki RAS, Paniago AMM, Lima Júnior MSC, Alencar DSO, Spositto FLE, Nunes MO, et al. First molecular typing of cryptococcemia-causing Cryptococcus in central-west Brazil. Mycopathologia. 2013;176(3-4):267-72.

25. Heppner HJ, Cornel S, Peter W, Philipp B, Katrin S. Infections in the elderly. Crit Care Clin. 2013;29(3):757-74. 
26. Leimann BCQ, Koifman RJ. Cryptococcal meningitis in Rio de Janeiro State, Brazil, 1994-2004. Cad Saude Publica. 2008;24(11):2583-92.

27. Lizarazo J, Escandón P, Agudelo CI, Castañeda E. Cryptococcosis in Colombian children and literature review. Mem Inst Oswaldo Cruz. 2014;109(6):797-804.

28. Corrêa MPSC, Oliveira EC, Duarte RRBS, Pardal PPO, Oliveira FM, Severo LC. Criptococose em crianças no estado do Pará. Brasil. Rev Soc Bras Med Trop. 1999;32(5):505-8.

29. Martins LMS, Wanke B, Lazéra MS, Trilles L, Barbosa GG, Macedo RCL, et al. Genotypes of Cryptococcus neoformans and Cryptococcus gattii as agents of endemic cryptococcosis in Teresina, Piauí (northeastern Brazil). Mem Inst Oswaldo Cruz. 2011;106(6):725-30.

30. Menezes T, Scain G, Quadros RM, Miletti LC, Souza AL, Miguel $\mathrm{RL}$, et al. Cryptococcus spp. em excretas de pombos (Columba livia) de áreas públicas de Lages, Santa Catarina. Sciense and Animal Health. 2014;2(2):102-14.

31. Takahara DT, Lazéra MS, Wanke B, Trilles L, Dutra V, Paula DAJ, et al. First report on Cryptococcus neoformans in pigeon excreta from public and residential locations in the metropolitan area of Cuiabá, State of Mato Grosso, Brazil. Rev Inst Med Trop São Paulo. 2013;55(6):371-6.

32. Filiú WFO, Wanke B, Agüena SM, Vilela VO, Macedo RCL, Lazéra M. Avian habitats as sources of Cryptococcus neoformans in the city of Campo Grande, Mato Grosso do Sul, Brazil. Rev Soc Bras Med Trop. 2002;35(6):591-5.

33. Moreira TA, Ferreira MS, Ribas RM, Borges AS. Criptococose: estudo clínico-epidemiológico, laboratorial e das variedades do fungo em 96 pacientes. Rev Soc Bras Med Trop. 2006;39(3):255-8.
34. Oliveira RB, Atobe JH, Souza SA, Santos DWCL. Epidemiology of invasive fungal infections in patients with acquired immunodeficiency syndrome at a reference hospital for infectious diseases in Brazil. Mycopathologia. 2014;178(1-2):71-8.

35. Vidal JE, Boulware DR. Lateral flow assay for cryptococcal antigen: an important advance to improve the continuum of HIV care and reduce cryptococcal meningitis-related mortality. Rev Inst Med Trop Sao Paulo. 2015;57(suppl 19):38-45.

36. Kidd SE, Hagen F, Tscharke RL, Huynh M, Bartlett KH, Fyfe M, et al. A rare genotype of Cryptococcus gattii caused the cryptococcosis outbreak on Vancouver Island (British Columbia. Canada). Proc Natl Acad Sci USA. 2004;101(49):17258-63.

37. Favalessa OC, de Paula DAJ, Dutra V, Nakazato L, Tadano T, Lazera MS, et al. Molecular typing and in vitro antifungal susceptibility of Cryptococcus spp from patients in Midwest Brazil. J Infect Dev Ctries. 2014;8(8):1037-43

38. Trilles L, Lazéra MS, Wanke B, Oliveira RV, Barbosa GG, Nishikawa MM, et al. Regional pattern of the molecular types of Cryptococcus neoformans and Cryptococcus gattii in Brazil. Mem Inst Oswaldo Cruz. 2008;103(5):455-62.

39. Matsumoto MT, Fusco-Almeida AM, Baeza LC, Melhem MS, Medes-Giannini MJ. Genotyping, serotyping and determination of mating-type of Cryptococcus neoformans clinical isolates from São Paulo State, Brazil. Rev Inst Med Trop Sao Paulo. 2007;49(1): 41-7.

40. Lomes NR, Melhem MS, Szeszs MW, Martins MA, Buccheri R. Cryptococcosis in non-HIV/non-transplant patients: a Brazilian case series. Med Mycol. 2016;54(7):669-76. 